\title{
Improving Interior Environmental Quality Using Sustainable Design in Jordanian Hospital Bedrooms
}

\author{
By Saeed Hussein Alhmoud ${ }^{1}$, Çiğdem Çağnan ${ }^{1}$, Enis Faik Arcan ${ }^{1}$
}

\begin{abstract}
As the wave of sustainability is sweeping across the major countries and cities of the world, the effect of the inevitable change is finding its way through to the health sector as well. Since the main functions of the hospital include healing the patient, it aims to provide adequate health services to people. Hospitals managers should strive to realize facilities that meet a certain level of demand. This study aims to present the interior environmental quality (IEQ) of bedrooms in Jordanian hospitals and propose a solution to improve indoor environment quality using sustainable design principles. A qualitative research methodology is used in this study. A comparative analysis is made between the original set up of the hospital buildings and the present conditions in which they are in. During the research, it was found that the design to be applied for a hospital should be following the healing environmental characteristics. Besides, the design of hospitals should be made with the climatic conditions of the area in mind. In the advanced countries of the world, hospitals are generally built with extensive research and important factors such as temperature, wind direction and humidity are taken into consideration. The design for a hospital building should be assessed according to the German Green Building Assessment (DGNB) criteria. It has been found that the one-bedroom is ideal for patients because it provides the necessary privacy and also greatly reduces the spread of the disease. In hygienic practices, there should be a first-class healing environment with evidence-based medical research. It was concluded that the practices involving the use of sustainable designs can be followed with the hints received from hospitals in the advanced countries of the world.
\end{abstract}

Keywords: Jordan hospital; IEQ; bedroom; interior design; healthcare; green building assessment; DGNB

\section{Introduction}

The perception of people about what wellness entail has led to an important shift in the architectural layout of the hospital environment, thus the improved result is felt in the health status of patients (Krauss et al., 2008) According to Lomas \& Giridharan (2012), even after the implementation of findings from research, the weight of arriving at a "healing environment" is further aided but does not guarantee its success. For it to be effective, Lomas \& Giridharan (2012) said the decisions arrived at must be designed to meet unique needs of the end users. People involved in the planning and design of hospitals are better served to stay up to date with occurrences and happenings that back the influence of healing environment on different individuals such as patients, their families, and healthcare personnel. The latest set of intelligence that has been gathered has emphasized the need for hospital designs to ensure recovery in the environment of the location. When the hospital environment is well designed and properly managed, with adequate spaces ensured in between structures and units, patients, visitors, and the hospital staff are better served and operations and activities can 
be carried out stress-free (Mc. Collugh, \& Humphreys, 2010; Castro et al., 2013). Hospitals in Jordan reflect a manifestation of the health care system and are in essence the spaces and institutions through which healthcare is administered to the public and are central to the process of healthcare. As such, they contribute to a large extent, the health quality of the Jordanian population through the services they offer. It is for this reason that such hospitals should be effectively organized and designed to give a positive effect on the "health and wellbeing" of the users. Although hospitals in Jordan are often designed without taking sufficient account of the outdoor conditions and indoor environmental satisfaction by the patients, workers, and visitors, there is some level of adjustment that can be carried out to cater to deficiencies.

There is a general lack of open spaces in hospitals where residents can relax out in the sun, play constructive games using decent lighting conditions in these hospitals can cause depressing traits in the patients amongst other things such as confusion, and staff medical errors. This study, therefore, seeks to understand the causes for the mismatch and propose solutions towards directing hospital design in Jordan towards improving patient's stay and staff operations.

\section{Hospital and Its Environment}

The implementation of hospital environment should be focused on the impact of the design structures on the different individuals that patronize the institution and should not be in a way that only ensures optimum service delivery (Rathert \& May, 2007; Eckelman \& Sherman, 2016). This is an obvious variation from the norms in the past. Instead, the direction has shifted towards designs that allow for quick patient recovery, stress alleviation, and good health status of patients, hospital staff, and visitors (Burpee, 2008). Initially, hospitals were not operated as commercial institutions. Rather, they were church-owned institutions before the responsibility shifted to communities. And as ownership changes, the structural design of their buildings changes as well to cater to some pressing needs over another (Ulrich, \& Gilpin, 2008; Elf et al., 2015). The earliest forms of hospitals are the ones that allow for a podium on a platform. These sorts of buildings provide adequate lighting exposure and ensure more exterior space (Pasanen et al., 2014). Another is the horizontal forms. Here, structures are constructed on the same placement, ensuring that wards and other sections of the hospital are placed side by side to each other. The main advantage of this sort of design is that it eliminates the problems associated with the upward/vertical movement of sick people which could too much stress for them to bear in their healing condition (Bachrach et al., 2012; Seyedahmadi, 2019).

Components of the Environment that Associates with Wellness: A huge percentage of budgets and allocation of any government administration goes into the health sector. This is meant to manifest in the quality of facilities and equipment on the ground, livelihood of staff, and quality health care delivery. It is given unfortunate that a lot of hospitals now serve as a source of disease infections for unsuspecting staff and patients alike (Bachrach et al., 2012; Eckelman \& Sherman, 2016). This is as a result of unpaid attention to the built environment, the components of which include;

- Lighting 
- Ventilation

- Effectiveness and Indoor Air Quality (IAQ)

- Acoustics

- Thermal Comfort

- Daylight and Views

Solutions for a Better Interior-Environment Quality in Hospitals: After a careful run through past work and literature, possible solutions are provided for the various problems that are stated for Indoor Environmental Quality (IEQ) are identified. The solutions are of different forms but are Design \& Construction Materials and Operations \& Maintenance (Yusoff \& Sulaiman, 2014).

Evidence-Based Design (EBD): Evidence-Based Design is a systematic approach to decision making that involves giving careful consideration to previous work and findings that have ensued on a particular model of the design of each specialized project (Rechel et al., 2009; Verderber et al., 2014). EBD usually focuses on certain important environmental features which are;

- Precise results if executed precisely

- Highly demanding when it comes to the cost of implementation

- Have a negative impact on patients and medical service delivery

- Subsequent works have set up on a model that takes a different path

Many of these include the installation of an efficient Heating Ventilation and Air Conditioning (HVAC) system, number and arrangement of patient beddings, hand washing basins, and general layout of health institutions. If decisions that are arrived at are well applied and followed, have the ability to up the ante in healthcare delivery, foster good and better communication and relationship, reduce stress in staff and patients and lead to increased satisfaction of patient in the quality of services that are rendered to them and state of the environment (Dascalaki et al., 2008; Yau \& Chew, 2009; Sadler et al., 2010).

\section{Analysis of Case Studies}

This is a qualitative study that aims to look at the evolutionary trends of hospital buildings from the initial design with which it was implemented. Inferential conclusions will be arrived at from the set of information gathered from various sources which will majorly be evaluated. The study compared the original set up of the hospital building and the present conditions in which they are in. This should not be difficult to adapt as changes are common in these forms of set up due to the operations they engage in from time to time. The mode of selection of the analysis of the case study approach because it provides the best contrasting and comparing differences and similarities between the 4 pre-selected Jordanian hospitals. They are; Islamic hospital, Aljazeerah hospital, Princess Rahma hospital, and Princess Basma hospital. Data will be collected on factors such as site planning of the hospitals, units and ward planning and arrangement, openings in rooms, and the materials used in the construction of the various parts including foundation, walls, and roof as all these affect the components of the natural environment in health.

Photographic images of both the interior and exterior of case studies were taken and also obtained from some reliable sources for a clear understanding of the current condition of the hospitals. The analyzed data were presented in tables, photographs, architectural 
drawings, and 3D images. Tables were used to make comparisons. Photographs were taken to make adequate observations of the case studies. 3D images and visualization were used to present computer-generated models to put the form and structure of the hospital components into a proper perspective.

Finally, after the completion of the findings, necessary recommendations made which will serve to provide templates to follow for professionals that are involved in erecting a building, in this case, hospital building and also the various stakeholders in the health care sector given assisting them to create an improved healing environment with reduced out of operation.

\subsection{Islamic Hospital (30 Beds)}

Islamic Hospital is an entrepreneurial hospital in Jordan. It is located at Rateb Al-Battayenah Street, Irbid, Jordan. The building was completed on the 12th of May, 2007. The total area of the entire hospital is about $2,720 \mathrm{~m}^{2}$, consisting of a total of six (6) floors with elevations and stairways. Specialized activities do go on at the hospital and have a very large labor force accepting staff in the excess of 75 comprising of the skilled and unskilled staff. There exists a certain level of vegetation close to the building providing shade and also serving as a windbreak. Parking space is spread across the face of the front entrance. There is also an extension beyond the walls of the hospital before the main road where vehicles can be parked (Table 1).

Table 1: Islamic Hospital

Explanation
- The building is a single structure that has all its
sectors in one.
- This way, the rooms in the building receive
maximum daylight and proper circulation of fresh air
is also ensured.
- At the frontal entrance, there are the stairs in steps
and also the pathway for those on wheelchairs to pass
through.
- There are trees close to the entrance and at a garden
close by. This provides shades and also eliminates
stale air.




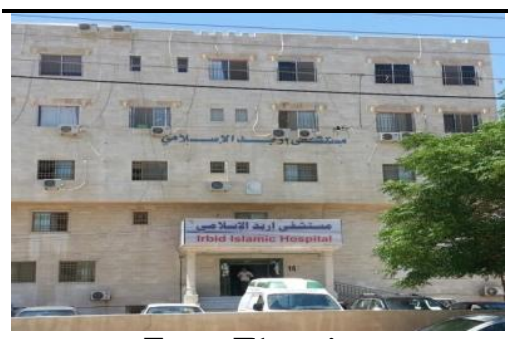

Front Elevation
- There are 2 general wards on the basement floor, the male ward consisting of 12 beds and the female ward having about 16.

- The middle floor is where the offices are and also an extension of the store.

- The topmost floors are where the intensive care units are which is an extension of 2 beds linked to the basement by elevator.

\subsection{Aljazeerah Hospital (55 Beds)}

Aljazeerah Hospital is located at the metropolitan city of Amman at Centre $\mathrm{Al}$ Jazeera, Haneen Bin Isac Street 8 on a total area of about 3,000 $\mathrm{m}^{2}$. Consisting of a total of four (4) floors it was built on the 17th of March, 2005. The plan that is copied by the hospital is a unique triangular shape with the central area providing enough space for gardening purposes. This hospital provides car drivers with quick and easy accessibility via its main door (Table 2).

Table 2: Aljazeerah Hospital

Explanation
an Islamic hospital.
- The parkway is to the front and sides of the
building.
- There are also trees close to the entrance.
- This provides shades and also freshen the air
in the hospital environment.




\subsection{Princess Rahma Hospital (126 Beds)}

A state hospital built on the 23rd of February, 1995. This is a public healthcare service center located at Zaki Al-Tall Street, Irbid, Jordan. Essential to mention the building consists of 3 -floor. The structure on the ground here consists of a compact unit with diverse sections feeding through a particular section and occupies a land area of about $10,540 \mathrm{~m}^{2}$ (Table 3).

Table 3: Princess Rahma Hospital

Explanation
- The hospital is spacious with segments
carved out got little flowering and gardening.
- A large deciduous tree is also available
therein for both aesthetics, shade and
replenishes stale air.
- Additionally, private wards have balconies
that add light penetration into the wards as
opposed to the general wards.

\subsection{Princess Basma Hospital (280 Beds)}

Princess Basma Hospital is a government-owned health institution that caters to the basic health needs of people and also carries out extensive administration of healing services and caring. The building consists of 3-floor sections. It is located at Faroud Haddad Street, Irbid, Jordan. The total land area is $9,580 \mathrm{~m}^{2}$. It was built on the 25th of May 1960 (Table 4). 
Table 4: Princess Basma Hospital

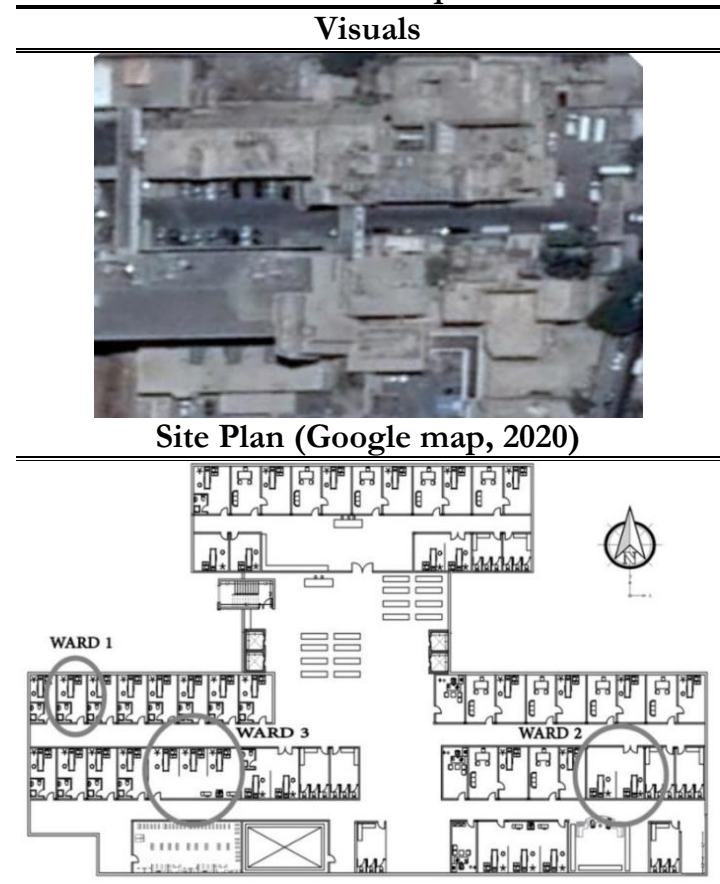

Explanation

- Trees and shades are at a premium here and winds do have easy access through the building.

- There is a central entrance at the front of the main building. It serves the major function of entry and exists by patients.

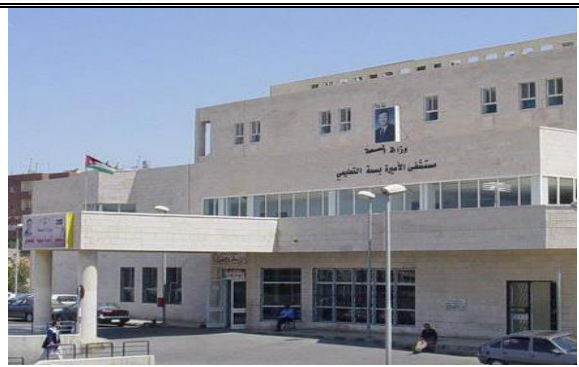

- The front part of the building is where the reception is and the general waiting room.

- The structure in the rare is where the children ward is sited with pathways lining across opposing bedrooms.

Front Partial Elevation

German Sustainable Building Council (Deutsche Gütesiegel Nachaltiges Bauen DGNB): Together with the Federal Ministry of Transport, Building and Urban Affairs (BMVBS) the German Sustainable Building Council (DGNB) developed a technique of building assessment that was delineated in 2008, once it had been conferred, as a secondgeneration assessment technique. The tactic addresses the buildings entire lifecycle and doesn't assess solely the operational part (Eberl, 2010; Schmidt, 2012; Markelj et al., 2013; Bahgat, 2016). The table below shows the evaluation of 4 hospitals according to DGNB criteria as; excellent, very good, good and poor.

The results obtained show the superiority in quality as with Aljazeerah, Princess Rahma and Princess Basma Hospital. Not with standing, Islamic hospital has also performed in an impressive manner as well. 
Table 5: Evaluation of case studies according to DGNB criteria

\begin{tabular}{|c|c|c|c|c|c|}
\hline & Criteria & $\begin{array}{l}\text { Islamic } \\
\text { Hospital }\end{array}$ & $\begin{array}{l}\text { Aljazeerah } \\
\text { Hospital }\end{array}$ & $\begin{array}{l}\text { Princess } \\
\text { Rahma } \\
\text { Hospital }\end{array}$ & $\begin{array}{l}\text { Princess } \\
\text { Basma } \\
\text { Hospital }\end{array}$ \\
\hline 1. & Local environmental impact & Very Good & Very Good & Very Good & Very Good \\
\hline 2. & Sustainable use of resources & Good & Good & Good & Good \\
\hline 3. & $\begin{array}{l}\text { Non-renewable primary } \\
\text { energy }\end{array}$ & Good & Good & Good & Good \\
\hline 4. & $\begin{array}{l}\text { Total primary energy } \\
\text { demand \& proportion of } \\
\text { renewable primary energy }\end{array}$ & Good & Good & Good & Good \\
\hline 5. & $\begin{array}{l}\text { Drinking water demand } \& \\
\text { volume of waste water }\end{array}$ & Very Good & Good & Very Good & Good \\
\hline 6. & Land use & Good & Good & Good & Good \\
\hline 7. & Thermal comfort in winter & Good & Good & Good & Good \\
\hline 8. & Indoor air quality & Good & Good & Very Good & Good \\
\hline 9. & Acoustic comfort & Poor & Poor & Poor & Poor \\
\hline 10. & Visual comfort & Good & Good & Good & Good \\
\hline 11. & Quality of outdoor space & Poor & Good & Poor & Poor \\
\hline 12. & Safety and security & Good & Good & Good & Good \\
\hline 13. & Accessibility & Very Good & Very Good & Very Good & Very Good \\
\hline 14. & Efficient use of floor area & Good & Good & Good & Good \\
\hline 15. & Suitability for conversion & Poor & Poor & Poor & Poor \\
\hline 16. & Integration of public art & Good & Good & Good & Good \\
\hline 17. & Fire prevention & Good & Good & Good & Good \\
\hline 18. & $\begin{array}{l}\text { Indoor acoustic and sound } \\
\text { insulation }\end{array}$ & Good & Good & Good & Good \\
\hline 19. & $\begin{array}{l}\text { Ease of cleaning and } \\
\text { maintenance }\end{array}$ & Very Good & Very Good & Very Good & Very Good \\
\hline 20. & $\begin{array}{l}\text { Ease of dismantling and } \\
\text { recycling }\end{array}$ & Poor & Poor & Poor & Poor \\
\hline 21. & $\begin{array}{l}\text { Integrated \& comprehensive } \\
\text { planning }\end{array}$ & Good & Very Good & Very Good & Very Good \\
\hline 22. & $\begin{array}{l}\text { Environmental impact of } \\
\text { construction site \& process }\end{array}$ & Poor & Poor & Poor & Poor \\
\hline 23. & $\begin{array}{l}\text { Public image \& social } \\
\text { conditions }\end{array}$ & Excellent & Excellent & Excellent & Excellent \\
\hline
\end{tabular}

The scores above in Table 5 represent the level at which each individual institution incorporate the guides of sustainable planning. The building contractors that are tasked in all the cases above took a lot of effort to ensure that the necessary features are put in place. These are however regarded as the strong points to be considered when installing a building in this modern age.

\section{Discussion: 3D Model Designs for a Sustainable IEQ in Jordanian Hospitals}

From the past, the practice that is accepted all over is the use of writings on a book for documentation. But with the extent of incorporation of technology into our day-to-day activities, the electronic register has been a faster, reliable, and effective replacement. With this, records of patients can be accessed anywhere in the world when stored on the internet. And even to ensure the decentralization of nurses work stations, 
computers are fitted at each bedside. This practice is assumed to have a great chance of evolving shortly into the use of a handheld system or mobile systems. All these processes will ensure the nursing staff is brought further closer to the patients.

The use of technological improvements in keeping track of supplies and inventory is also important. There is the need to utilize a central automated dispensing unit as opposed to storing supplies in the room as there can be a need for topping off a depleting stock is cared for in time.

The issue of privacy is not to be overlooked also, with an increasing number of beds in a room; the level of privacy is naturally reducing. While the space afforded will conveniently take more than a bed in some 2,3 or 4-bed unit, the use of fabric curtain elements to create some kind of partition is a welcome idea.

The universal room setting reduces the extent to which they consider the acoustic and visual privacy of patients. This has also led to the debate of the need to initiate the use of more inboard toilets instead of outboard ones.

While some hospitals allow family members of inpatients of visitors to rest or pass their time at the lounge, a better and more convenient model allows the use of sitting materials that can be suspended into the bedding.

3D Model designs for a sustainable IEQ in Jordanian Hospitals are properly represented in the case studies that were discussed. These plans took some important elements into account such as spaciousness and comfortability. The maximization of spaces in the case of 2 and 3-bed rooms still provided an avenue to accommodate all the essential components of a room while the main goal of achieving an excellent IEQ is still sustained. Table 6 shows the 3D design of 1-bed ward \& 2-bed ward while table 7 shows a typical 3-bed ward \& a consultation room. The designs have taken into account the components of sustainability and they are properly managed making the models respected blueprints for any future hospital design.

Serenity in the environment: Patients feel safer in a conducive environment which gradually improves their wellbeing as they get better. In ensuring that they feel comfortable and unstressed, the interior design plays a major role in ensuring this. They can best accomplish this goal by having a clear sense of purpose of the institution and the profile of the patient, including having hands-on information such as sight impairment, old age, mental instability, or physical challenges.

Good hygiene practices: Some guides can be factored in the designing of hospital rooms to ensure proper hygiene and satisfaction is followed such as making sure that the finishing of spaces where regular activities go on should be durable, Points and junctions where edges/surfaces meet are better detailed in such a way that it does not hold dust while also teaching people on the need to ensure cleanliness and how to better operate newly adopted features.

Adequate ventilation: The hospital is usually of a big structure that contains a lot of rooms and sections. Thus, if care is not taken in the planning process, the flow and cross ventilation in the building may be inhibited.

Aesthetics: This is not entirely different from creating a serene scene in the hospital environment. To give health institutions a facelift, it's good for its image and serves as an important marketing tool when the aesthetic value is properly managed. It also helps to improve staff morale and healing nature. 


\section{Other considerations to be observed are thus as follows;}

- The flooring of the entire building especially where patients have access to should not be slippery.

- Besides, floors should be easy to clean and made of durable materials.

- The outer layer of walls of paintings should be that which does not retain dust.

- Any ground openings should be closely covered in case of plumbing and wiring works.

- Doors should be either sliding or swing type and should be lubricated when signs of rustiness are noticed.

- Curtains should be fireproof and easily maintained.

- A mini locker or side table should be provided inwards.

- A means of communication or a device for reaching the medical staff should be provided at each bedside.

Table 6: 3 D design of 1-bed ward and 2-bed ward (Alhmoud, 2020)

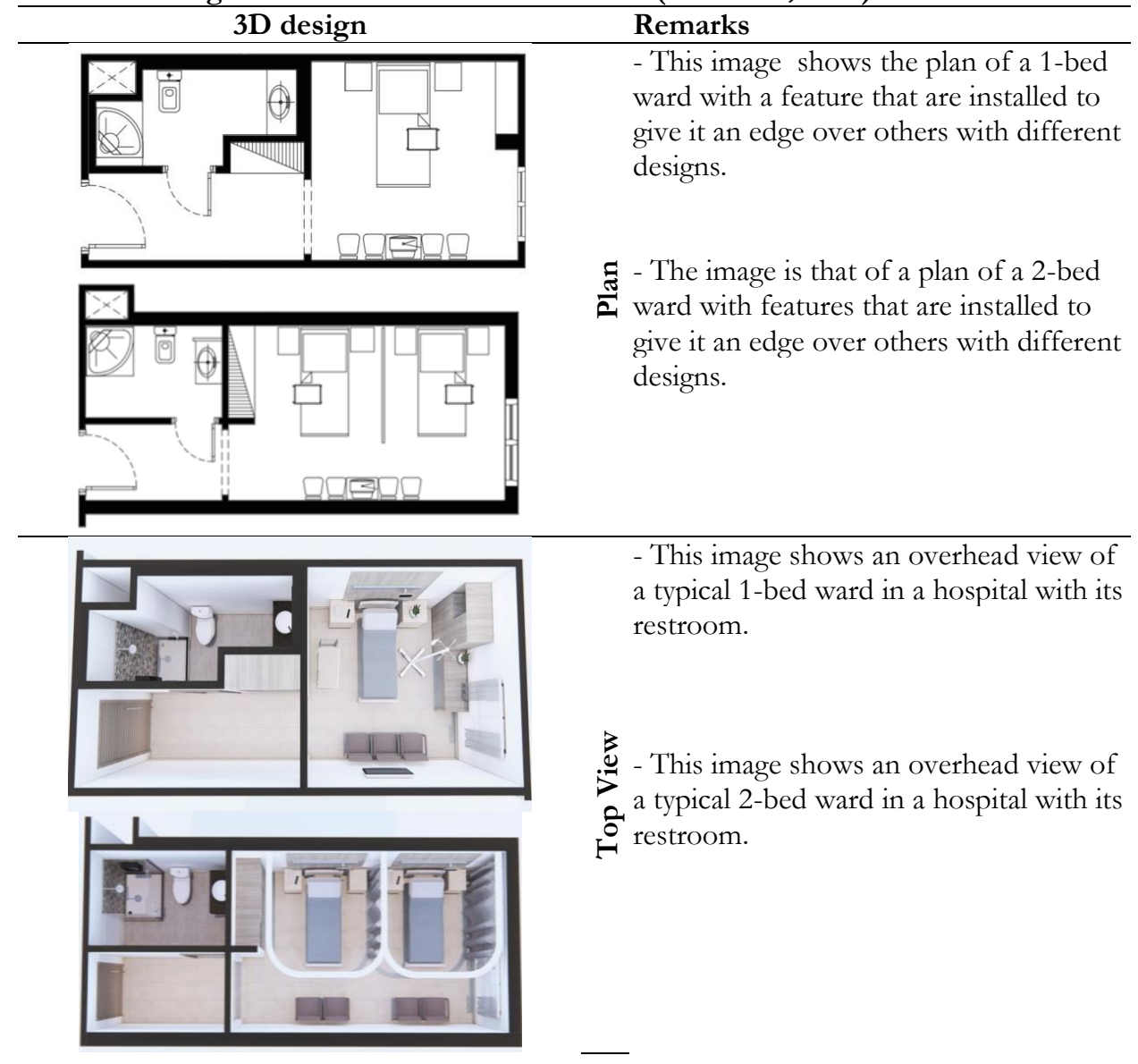




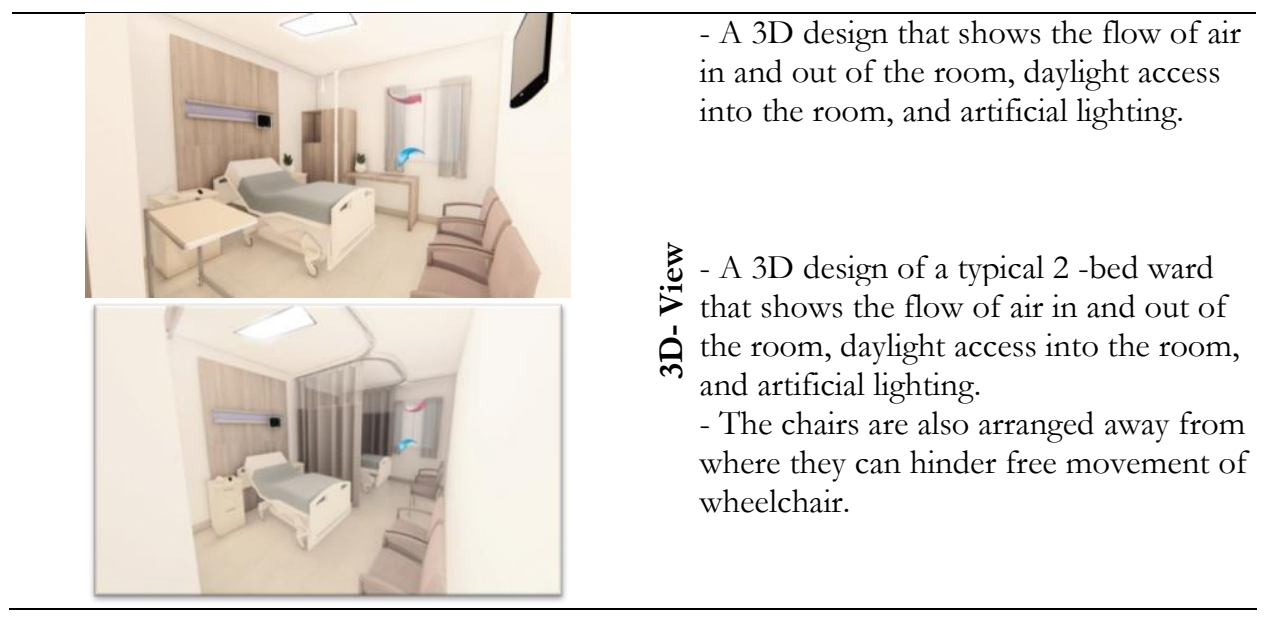

Table 7: 3 D design of 3-bed ward and a consulting room (Alhmoud, 2020)

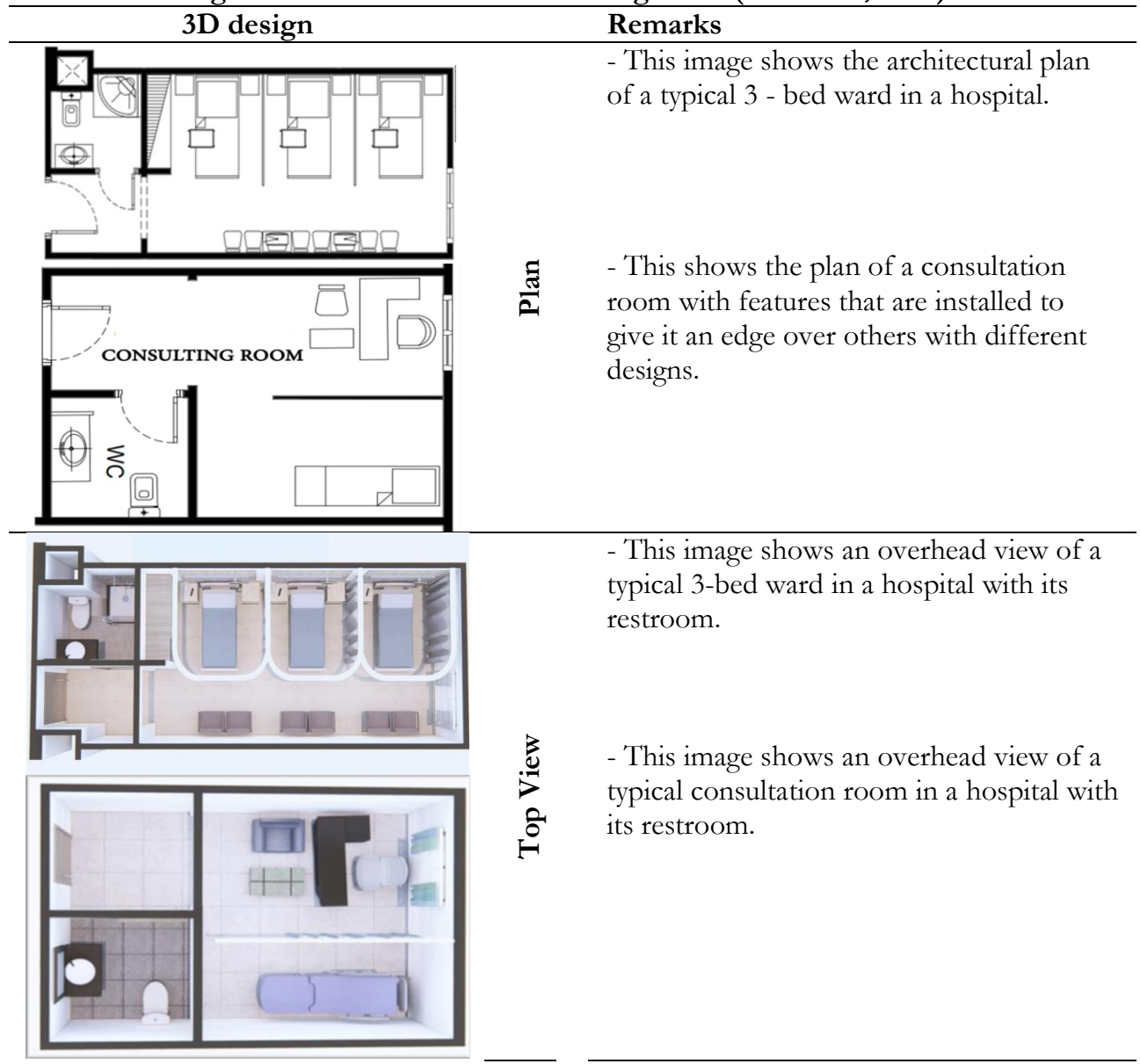




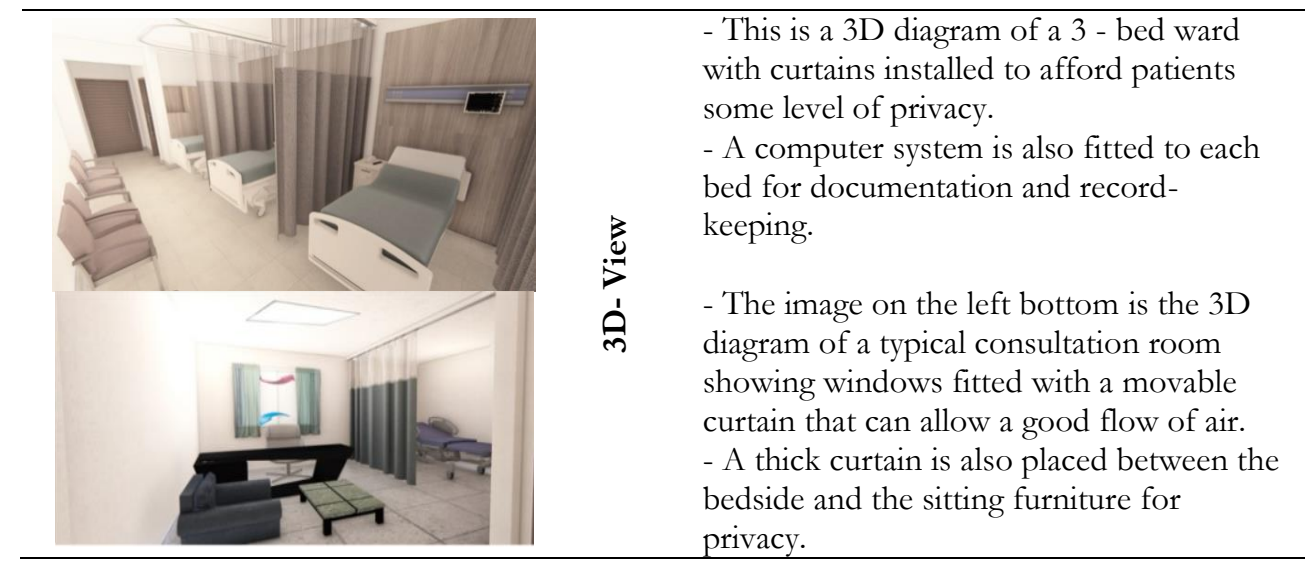

\section{Conclusion and Recommendations}

If during the planning of a building, some latent factors are not accounted for, they may end up finding a suitable platform to cause HVAC. These factors are usually inactive in the system for a long period but will combine with other elements to carry out their destructive actions. On the bright side, these issues can be identified and an appropriate solution can be provided. These hidden factors include;

- Badly organized facilities

- Wrongly stated procedures

- Poor safety system

- Wrongly placed equipment and staff inadequacies

A good example of latent conditions interfering with proper clinical efficiency is a poor lighting model employed in a section where drugs are dispensed which can lead to error in the administration of medication. To deal with this, measures that can be taken to tackle this situation are;

- Adequate staff numbers in stations

- Sensitization of staff and other hospital users on basic operational procedures

- Use of evidence-based design to limit distractions

- Improved positioning of movables and other supplies

- Ensure adequate spacing in key operational areas

With respect to the basic components of a hospital, some templates are made which are import and can go a long way to make designer arrive at a rich outcome. They are;

- Patient-oriented design.

- Adhering to the use of 1-bedroom.

- The rooms should be spacious enough to accommodate visitors i.e. family and friends

- The health profile of the patients should be considered

- Directions and inscriptions of pathways should be created within the hospital for easy navigation safety, planning of structures i.e. non-slippery floors and the use of supportive installations to prevent fall, the HVAC system should be up and running and maximum control should be exercised on it to limit the spread of communicable diseases, adopting the use of surfaces that do not absorb stains and dirt and can be easily cleaned, and also 
alcohol-based washer and sink should be provided at the entrance of rooms.

\section{Acknowledgment}

This article is generated from the master's thesis entitled Improving Interior Environmental Quality Using Sustainable Design in Jordanian Hospital Bedrooms, prepared by Saeed Hussein Alhmoud at the Near East University, under the supervision of Assist. Prof. Dr. Çiğdem Çă̆nan.

\section{References}

Alhmoud, Saeed Hussein (2020). Improving Interior Environmental Quality Using Sustainable Design in Jordanian Hospital Bedrooms [Unpublished master's thesis]. Near East University, Graduate School of Applied Sciences, Nicosia, Cyprus.

Bachrach, D., Braslow, L., \& Karl, A. (2012). Toward a high performance health care system for vulnerable populations: funding for safety-net hospitals. The Commonwealth Fund.

Bahgat, H. (2016). Government Policy as a Driver of Energy Saving in Egypt. European Journal of Sustainable Development, 5(4), 549-549.

Burpee, H. (2008). History of Healthcare Architecture: Integrated Design Lab Puget Sound.

Castro, M. D. F., Mateus, R., \& Bragança, L. (2013). Improving sustainability in healthcare with better space design quality. Green Design, Materials and Manufacturing Processes, 101-106.

Dascalaki, E. G., Lagoudi, A., Balaras, C. A., \& Gaglia, A. G. (2008). Air quality in hospital operating rooms. Building and Environment, 43(11), 1945-1952.

Eberl, S. (2010, June). DGNB vs. LEED: A comparative analysis. In Conference on Central Europe towards Sustainable Building, CESB10 Prague: 1-5.

Eckelman, M. J., \& Sherman, J. (2016). Environmental impacts of the US health care system and effects on public health. PloS one, 11(6), e0157014.

Elf, M., Fröst, P., Lindahl, G., \& Wijk, H. (2015). Shared decision making in designing new healthcare environments-time to begin improving quality. BMC health services research, 15(1), 114.

Krauss, M. J., Tutlam, N., Costantinou, E., Johnson, S., Jackson, D., \& Fraser, V. J. (2008). Intervention to prevent falls on the medical service in a teaching hospital. Infection Control \& Hospital Epidemiology, 29(6), 539-545.

Lomas, K. J., \& Giridharan, R. (2012). Thermal comfort standards, measured internal temperatures and thermal resilience to climate change of free-running buildings: A case-study of hospital wards. Building and Environment, 55, 57-72.

Malkin, J. Hospital Interior Architecture: Creating Healing Environments for Special Patient Populations. ISBN-13: 978-0471289760, ISBN-10: 0471289760.

Markelj, J., Kitek Kuzman, M., \& Zbašnik-Senegačnik, M. (2013). A review of building sustainability assessment methods. Archit. Res, 1, 22-31.

Mc. Collugh, J., \& Humphreys, M. (2010). Adaptive thermal comfort and sustainable thermal standards for buildings. Energy and Buildings, 34 (60), 563-572.

Pasanen, T. P., Tyrväinen, L., \& Korpela, K. M. (2014). The relationship between perceived health and physical activity indoors, outdoors in built environments, and outdoors in nature. Applied Psychology: Health and Well-Being, 6(3), 324-346.

Rathert, C., \& May, D. R. (2007). Health care work environments, employee satisfaction, and patient safety: Care provider perspectives. Health care management review, 32(1), 2-11.

Rechel, B., Buchan, J., \& McKee, M. (2009). The impact of health facilities on healthcare workers' well-being and performance. International Journal of Nursing Studies, 46(7), 1025-1034.

Sadler, B. L., Berry, L. L., Guenther, R., Hamilton, D. K., Hessler, F. A., Merritt, C., \& Parker, D. (2011). Fable hospital 2.0: the business case for building better health care facilities. Hastings Center Report, 41(1), 13-23. 
Schmidt, A. (2012). Analysis of five approaches to environmental assessment of building components in a whole building context. Force Technology, Lyngby.

Seyedahmadi, S. (2019). Role of Natural Elements in Provision of Healing Environment: Sustainable Healthcare Building. European Journal of Sustainable Development, 8(1), 401-401.

Ulrich, R. S., \& Gilpin, L. (2008). Healing arts: Nutrition for the soul. In S. B. Frampton, L. Gilpin \& P. Charmel (Eds.), Putting patients first: Designing and practicing patient-centered care (pp. 117146). San Francisco: Jossey-Bass.

Verderber, S., Jiang, S., Hughes, G., \& Xiao, Y. (2014). The evolving role of evidence-based research in healthcare facility design competitions. Frontiers of Architectural Research, 3(3), 238-249.

Yau, Y., \& Chew, B. (2009). Thermal comfort study of hospital workers in Malaysia. Indoor Air, (19), 500510.

Yusoff, W. Z. W., \& Sulaiman, M. A. (2014). Sustainable campus: Indoor Environmental Quality (IEQ) performance measurement for Malaysian public universities. European Journal of Sustainable Development, 3(4), 323-323. 